Research Article

\title{
Surface Albedo Assimilation and Its Impact on Surface Radiation Budget in Beijing
}

\author{
Chunlei Meng (iD \\ Institute of Urban Meteorology, China Meteorological Administration, Beijing 100089, China \\ Correspondence should be addressed to Chunlei Meng; clmeng@ium.cn
}

Received 10 January 2020; Accepted 24 February 2020; Published 2 June 2020

Academic Editor: Eduardo García-Ortega

Copyright (c) 2020 Chunlei Meng. This is an open access article distributed under the Creative Commons Attribution License, which permits unrestricted use, distribution, and reproduction in any medium, provided the original work is properly cited.

\begin{abstract}
Surface albedo is a crucial parameter in land surface radiation budget. As bias exists between the model simulated and observed surface albedo, data assimilation is an important method to improve the simulation results. Moreover, surface albedo is associated with the wavelength of the sunlight. So, solar radiation partitioning is important to parameterize the surface albedo. In this paper, the moderate resolution imaging spectroradiometer- (MODIS-) retrieved direct visible, direct near-infrared, diffuse visible, and diffuse near-infrared surface albedos were assimilated into the integrated urban land model (IUM). The solar radiation partitioning method was introduced to parameterize the surface albedo. Based on the albedo data from MODIS and the solar radiation partitioning method, the surface albedo data set for the Beijing municipal area was generated. Based on the surface albedo data set and the IUM, the impacts of the surface albedo on the surface radiation budget were discussed quantitatively. Surface albedo is inversely proportional to the net radiation. For urban areas, after assimilation, the annual average net radiation decreases about 5.6\%. For cropland, grassland, and forest areas, after assimilation, the annual average net radiations increase about $20.2 \%, 24.3 \%$, and $18.7 \%$, respectively.
\end{abstract}

\section{Introduction}

Surface albedo is a crucial parameter in land surface radiation budget [1]. The parameterization of surface albedo is important in land-atmosphere interaction and coupling [1-8]. Surface albedo is not only associated with the soil moisture, soil color, and solar zenith angle [9-15] but also associated with the wavelength of the solar radiation $[16,17]$. Although progress has been made in surface albedo simulation by land surface models, biases $[10,18]$ still exist inevitably between the simulation and observation.

Compared with the model simulation, surface albedo data retrieved from remote sensing images have their advantages [19-23] and are used and assimilated [21, 24-27] into the land surface models. Among them, surface albedo from the moderate resolution imaging spectroradiometer (MODIS) $[18,24-34]$ is one of the most widely used products. Unfortunately, for most of the assimilation methods $[25-27,31]$, the effect of the solar radiation partition $[17,35]$ is not included. In fact, the surface albedos for visible and near-infrared solar radiations are quite different
[17]; solar radiation partitioning is important to parameterize the surface albedo.

In this paper, the MODIS-retrieved direct visible, direct near-infrared, diffuse visible, and diffuse near-infrared surface albedos were assimilated into the integrated urban land model (IUM). The solar radiation partitioning method [17] was introduced to parameterize the surface albedo to consider the effect of the wavelength of the solar radiation. Based on the surface albedo data from MODIS and the solar radiation partitioning method, the surface albedo data set for the Beijing municipal area was generated. Based on the surface albedo data set and the IUM, the impacts of the surface albedo on surface radiation budget were discussed quantitatively.

\section{Data and Method}

2.1. Study Area. The study area of this paper is the Beijing municipal area. The research region is located at $39.3^{\circ}-41.1^{\circ} \mathrm{N}, 115.2^{\circ}-117.6^{\circ} \mathrm{E}$. The terrain tilts from northwest to southeast (Figure 1(a)). The dominate land cover 


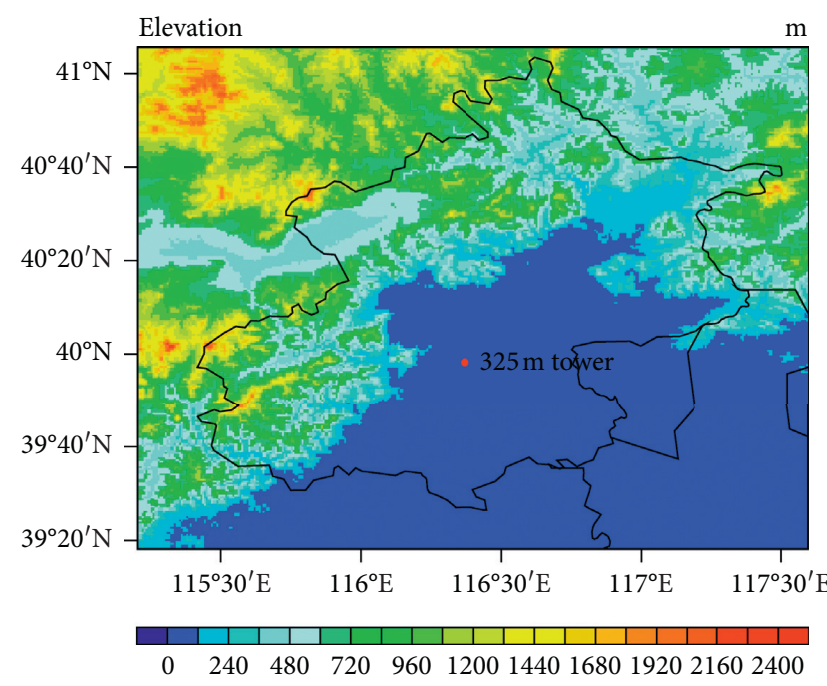

(a)

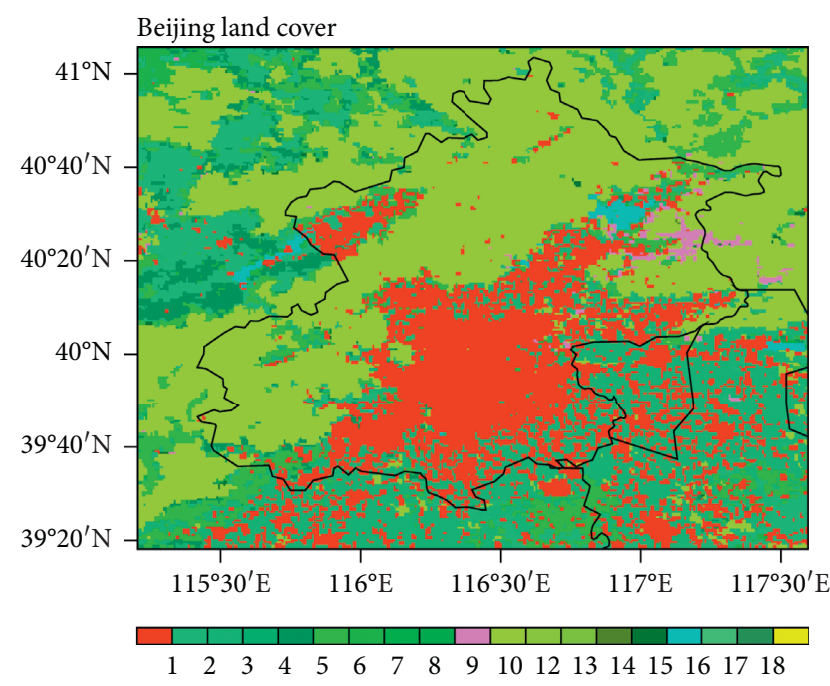

(b)

FIGURE 1: (a) Shaded relief elevation above sea level (m) and the position of the $325 \mathrm{~m}$ tower; (b) USGS LUCs based on MODIS (1, urban and built-up land; 2, dryland cropland and pasture; 3, irrigated cropland and pasture; 4, mixed dryland/irrigated cropland and pasture; 5 , cropland/grassland mosaic; 6, cropland/woodland mosaic; 7, grassland; 8, shrubland; 9, mixed shrubland/grassland; 10, savanna; 11, deciduous broadleaf forest; 12 , deciduous needleleaf forest; 13 , evergreen broadleaf forest; 14, evergreen needleleaf forest; 15 , mixed forest; 16, water bodies; 17, herbaceous wetland; 18 , wooded wetland; 19 , barren or sparsely vegetated).

category (LUC) in each grid is based on MODIS $1 \mathrm{~km}$ resolution data in 2017 (Figure 1(b)). The LUCs were transferred from International Geosphere-Biosphere Programme (IGBP) classification to United States Geological Survey (USGS) classification using the relationship listed in Table 1. The Chinese Academy of Sciences $325 \mathrm{~m}$-high Meteorology and Environmental Observation Tower $(325 \mathrm{~m}$ tower) was located in downtown Beijing, and the longitude and latitude of the $325 \mathrm{~m}$ tower are $116.37 \mathrm{E}$ and $39.97 \mathrm{~N}$, respectively (Figure $1(\mathrm{a})$ ).

2.2. Data. The $325 \mathrm{~m}$ tower data were used for the surface albedo data comparison. The tower is located in downtown Beijing, and the altitude of the foot of the tower is $49 \mathrm{~m}$. The radiation fluxes including the upward and downward shortwave and longwave radiation are measured using the radiometer at the 47-meter height. The time ranges of the observed upward and downward shortwave radiation are from March to October 2018. The observed surface albedo is calculated as follows:

$$
\alpha=\frac{S \uparrow}{S \downarrow},
$$

where $\alpha$ is the surface albedo; $S \uparrow$ is the upward shortwave radiation $\left(\mathrm{W} \mathrm{m}^{-2}\right)$; and $S \downarrow$ is the downward shortwave radiation $\left(\mathrm{W} \mathrm{m}^{-2}\right)$.

The albedos for direct visible, direct near-infrared, diffuse visible, and diffuse near-infrared solar radiations are from MODIS in 2015. The temporal and spatial resolution of the MODIS albedo data are $8 \mathrm{~d}$ and $1 \mathrm{~km}$, respectively. The MODIS albedo products were spliced and clipped firstly; then, they were interpolated linearly from $8 \mathrm{~d}$ to $1 \mathrm{~d}$.

The atmospheric forcing data used to drive the land surface model are originated from the Global Land Data Assimilation System (GLDAS) [36]. The initial field data are also originated from GLDAS. The temporal resolution of GLDAS is $3 \mathrm{~h}$. The spatial resolution of GLDAS data is $0.25^{\circ}$, which was interpolated to $1 \mathrm{~km}$ by using a bilinear interpolation method.

2.3. Land Model. We employed the integrated urban land model (IUM) [37] to study the impact of the surface albedo on radiation budget. IUM was developed based on the common land model (CoLM) [38]. IUM integrates the land surface models for urban and natural land surfaces.

2.4. Surface Albedo Parameterization. The surface albedo for bare soil [15] in the IUM could be described as follows:

$$
\begin{aligned}
\alpha_{\text {vis,soil }} & =0.22 \times\left[1+\exp \left(-0.15 \times h_{\theta}\right)\right]-0.45 \times \theta, \\
\alpha_{\text {nir,soil }} & =0.26 \times\left[1+\exp \left(-0.15 \times h_{\theta}\right)\right]-0.45 \times \theta, \\
\alpha_{\text {soil }} & =\frac{\left(\alpha_{\text {vis,soil }}+\alpha_{\text {nir,soil }}\right)}{2},
\end{aligned}
$$

where $h_{\theta}$ is the solar elevation angle $\left({ }^{\circ}\right) ; \theta$ is the volumetric soil moisture; $\alpha_{\text {vis,soil }}$ and $\alpha_{\text {nir,soil }}$ are the albedos for visible and near-infrared solar radiations, respectively; and $\alpha_{\text {soil }}$ is the albedo for bare soil. The surface albedo for urban in the IUM could be described as follows: 
TABLE 1: Land use and land cover (LULC) mapping between the IGBP and the USGS classifications.

\begin{tabular}{lcc}
\hline LULC type & IGBP ID & USGS ID \\
\hline Water & 0 & 0 \\
Evergreen needleleaf forest & 1 & 14 \\
Evergreen broadleaf forest & 2 & 13 \\
Deciduous needleleaf forest & 3 & 12 \\
Deciduous broadleaf forest & 4 & 11 \\
Mixed forest & 5 & 15 \\
Closed shrublands & 6 & 8 \\
Open shrublands & 7 & 8 \\
Woody savannas & 8 & 10 \\
Savannas & 9 & 10 \\
Grasslands & 10 & 7 \\
Permanent wetlands & 11 \\
Croplands & 12 \\
Urban and built-up & 13 \\
Cropland/natural vegetation mosaic & 14 \\
Snow and ice & 15 & 4 \\
Barren or sparsely vegetated & 16 & 24 \\
\hline
\end{tabular}

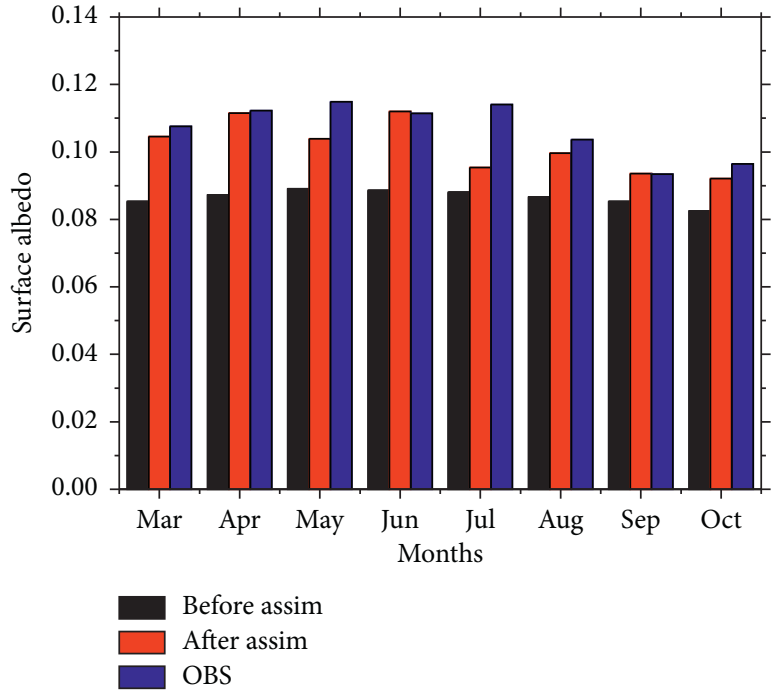

(a)

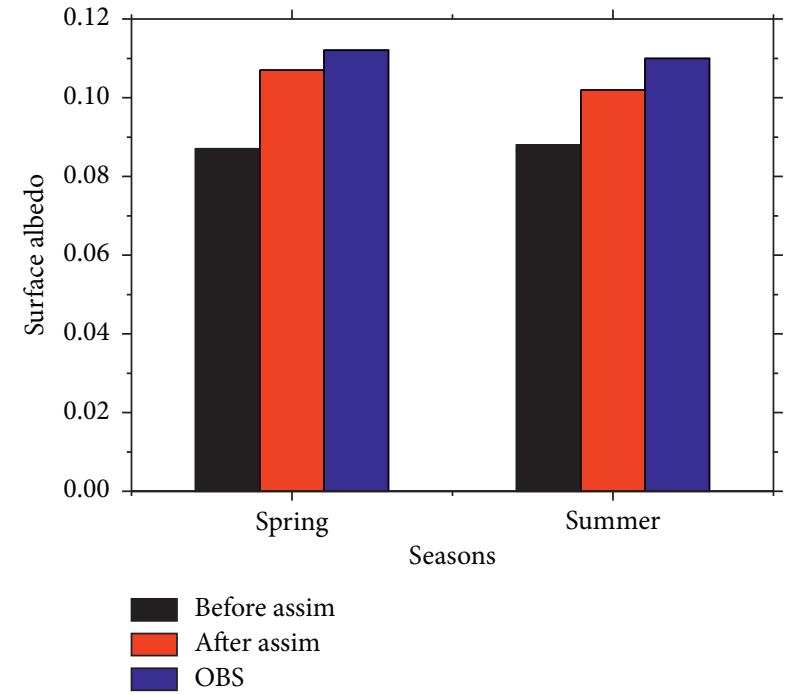

(b)

Figure 2: Monthly (a) and seasonal (b) average surface albedo simulations before and after assimilation and the observations.

$$
\begin{aligned}
\alpha_{\text {vis,urb }} & =0.15 \times\left[1+\exp \left(-0.15 \times h_{\theta}\right)\right]-0.45 \times \theta, \\
\alpha_{\text {nir,yrb }} & =0.3 \times\left[1+\exp \left(-0.15 \times h_{\theta}\right)\right]-0.45 \times \theta, \\
\alpha_{\text {urb }} & =\frac{\left(\alpha_{\text {vis,urb }}+\alpha_{\text {nir,urb }}\right)}{2},
\end{aligned}
$$

where $\alpha_{\text {vis,urb }}$ and $\alpha_{\text {nir,urb }}$ are the albedos for visible and nearinfrared solar radiations, respectively, and $\alpha_{\text {urb }}$ is the albedo for urban. The surface albedo for vegetated surfaces is the same as that in the CoLM. A two-stream approximation method is used to parameterize it. The grid point surface albedo is calculated as follows:

$$
\alpha=\alpha_{\text {soil }} \times f_{\text {soil }}+\alpha_{\text {urb }} \times f_{\text {urb }}+\alpha_{\text {veg }} \times f_{\text {veg }},
$$

where $\alpha_{\text {veg }}$ is the albedo for vegetation and $f_{\text {soil }}, f_{\text {urb }}$, and $f_{\text {veg }}$ are the fractional cover for soil, urban, and vegetation, respectively.
In this paper, the moderate resolution imaging spectroradiometer- (MODIS-) retrieved direct visible, direct near-infrared, diffuse visible, and diffuse near-infrared surface albedos were assimilated into the integrated urban land model (IUM). The solar radiation partitioning method was introduced to parameterize the surface albedo. The assimilation algorithm is as follows:

$$
\alpha=R_{\mathrm{d} v} \times \alpha_{\mathrm{vis}, \mathrm{dir}}+R_{\mathrm{d} n} \times \alpha_{\mathrm{nir}, \mathrm{dir}}+R_{f v} \times \alpha_{\mathrm{vis}, \mathrm{dif}}+R_{f n} \times \alpha_{\mathrm{nir}, \mathrm{dif}},
$$

where $R_{\mathrm{d} v}, R_{f v}, R_{\mathrm{d} n}$, and $R_{f n}$ are direct visible, diffuse visible, direct near-infrared, and diffuse near-infrared solar radiations $\left(\mathrm{W} \mathrm{m}^{-2}\right)$, respectively; they are calculated based on Weiss and Norman [35] and corrected to consider the effect of cloud cover [17]. $\alpha_{\text {vis,dir }}, \alpha_{\text {nir,dir }}$, $\alpha_{\text {vis,dif }}$, and $\alpha_{\text {nir,dif }}$ are albedos for direct visible, direct near-infrared, diffuse visible, and diffuse near-infrared 
TABLE 2: Biases between the monthly average surface albedo simulations before and after assimilation and the observations (simulation minus observation).

\begin{tabular}{lcc}
\hline Month & Bias/old & Bias/new \\
\hline March & -0.022 & -0.003 \\
April & -0.025 & -0.001 \\
May & -0.026 & -0.011 \\
June & -0.023 & 0.001 \\
July & -0.026 & -0.019 \\
August & -0.017 & -0.004 \\
September & -0.008 & 0.0002 \\
October & -0.014 & -0.004 \\
\hline
\end{tabular}
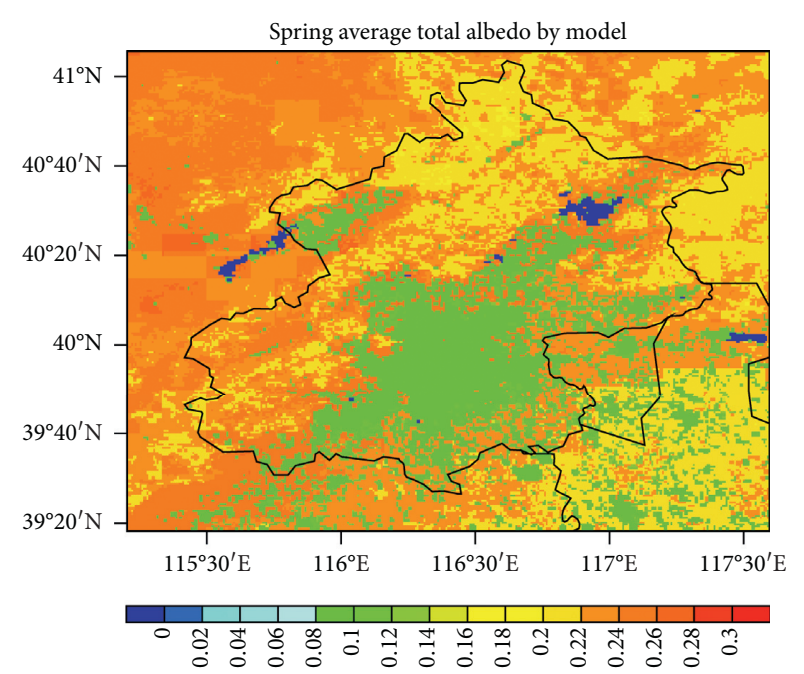

(a)

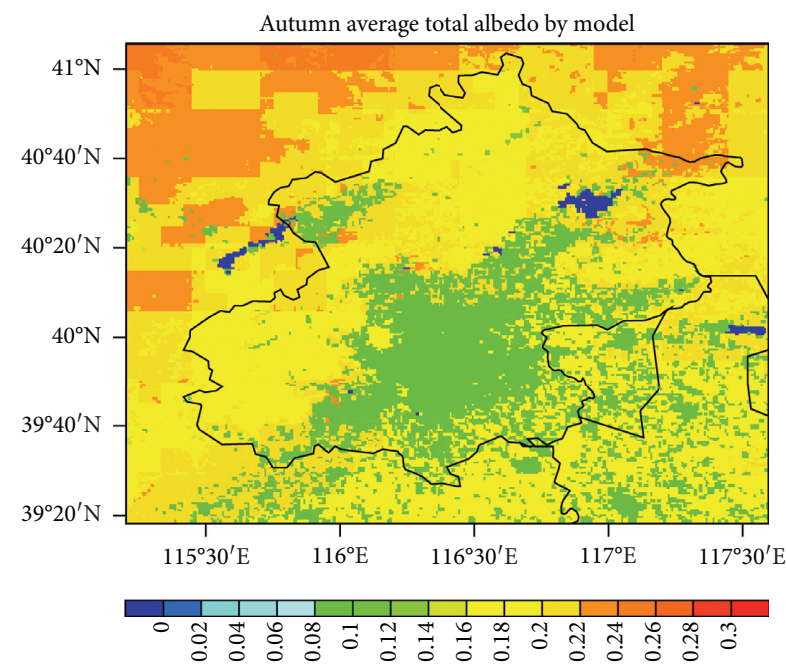

(c)

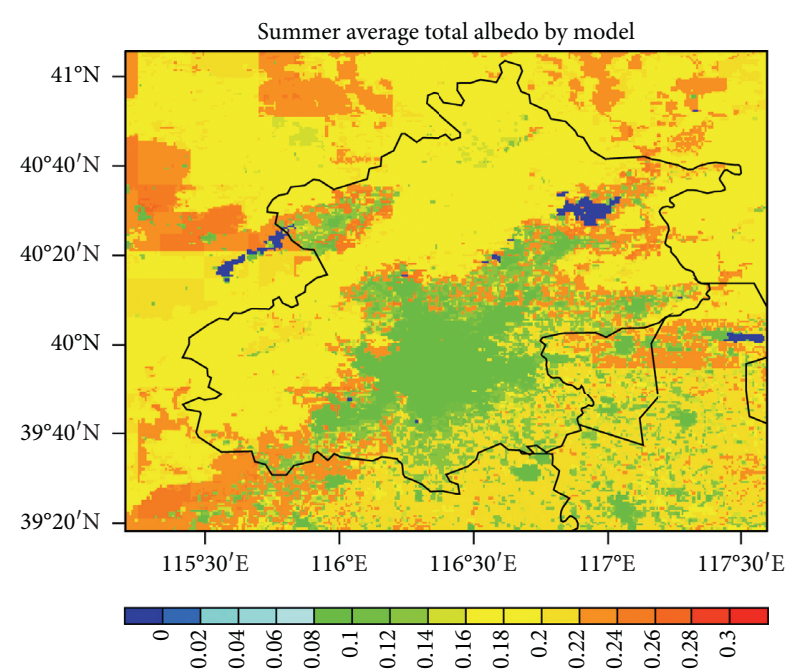

(b)

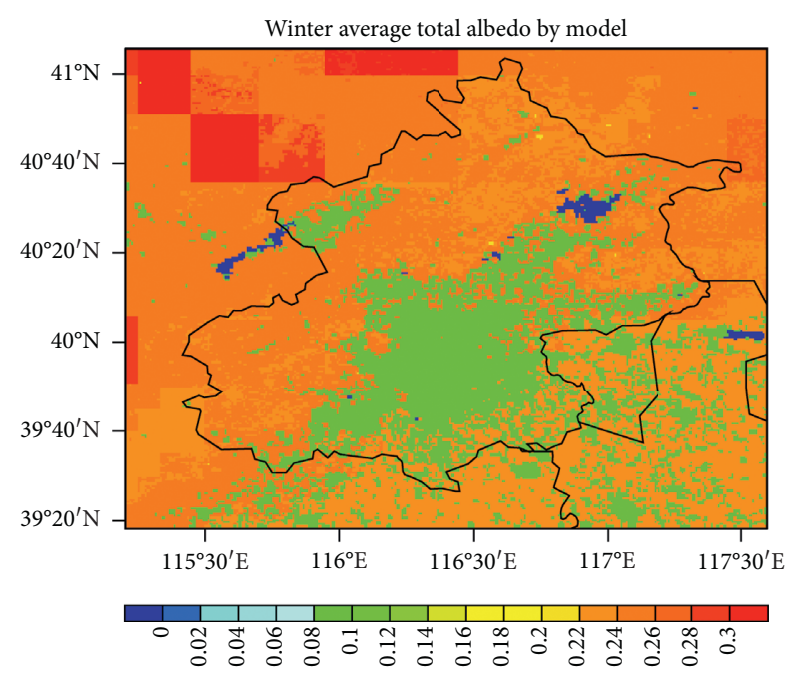

(d)

FIgURE 3: Continued. 


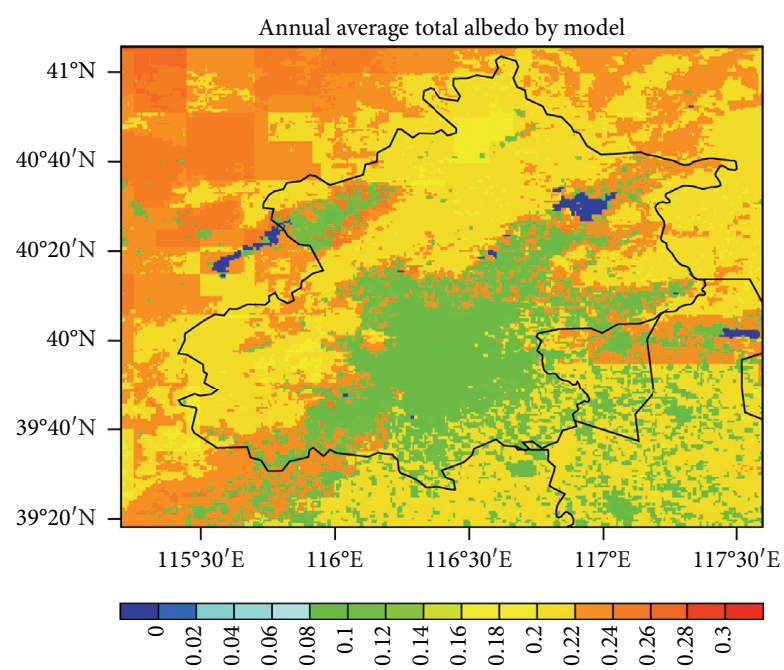

(e)

Figure 3: Spatial distribution of the annual (e) and seasonal (a-d) average surface albedo simulations before assimilation in the Beijing municipal area.

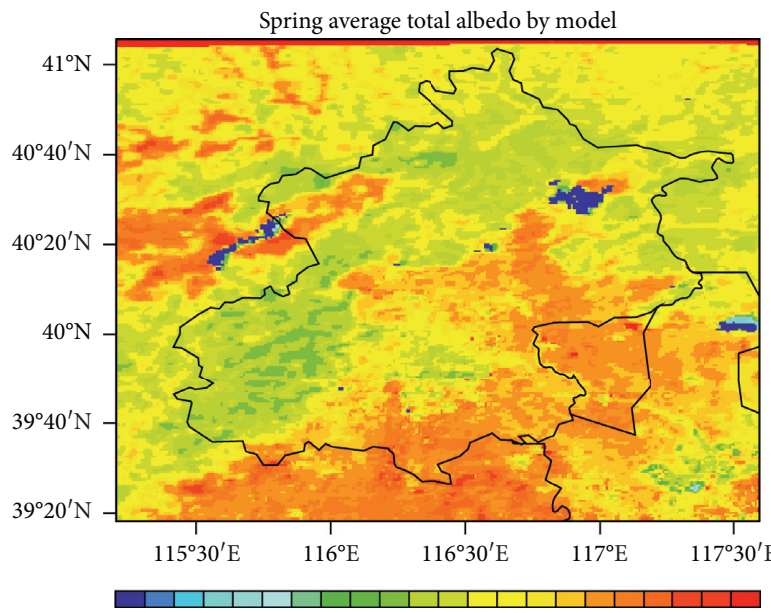

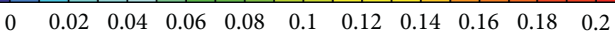

(a)

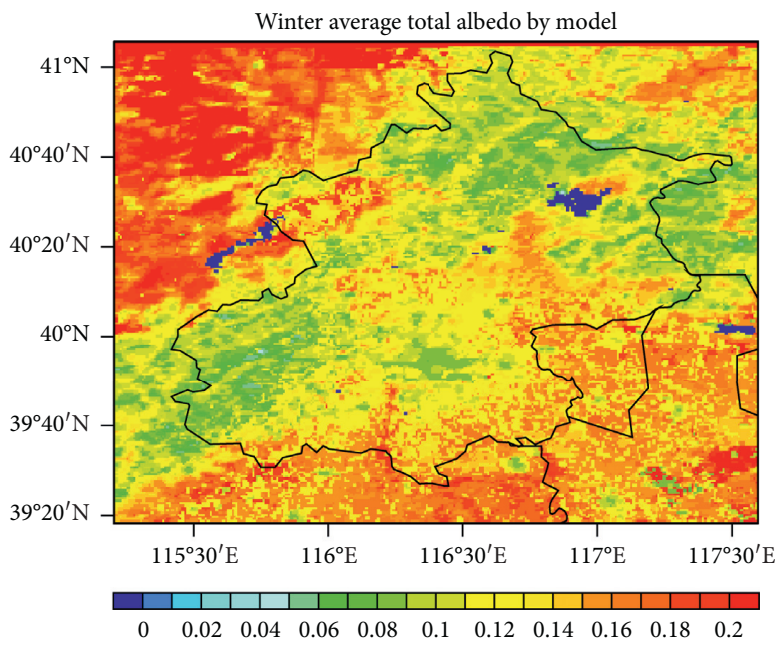

(c)

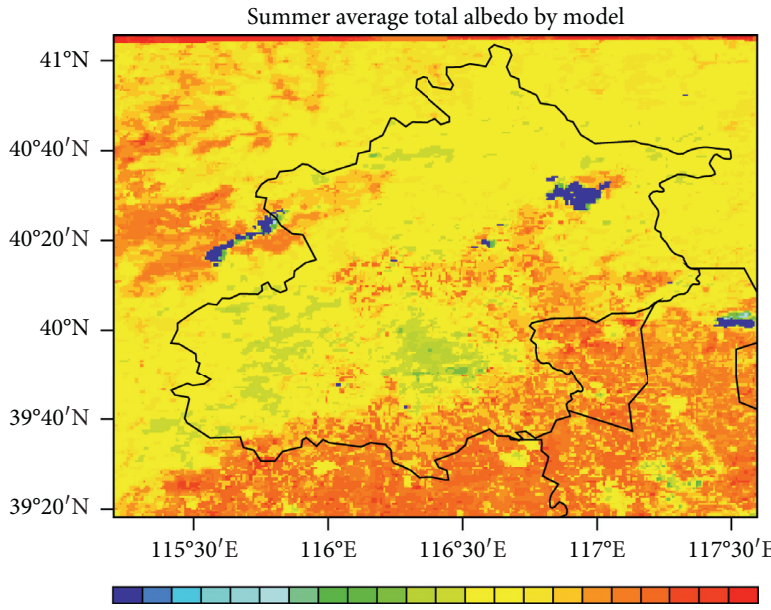

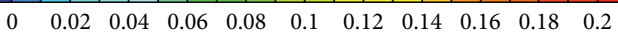

(b)

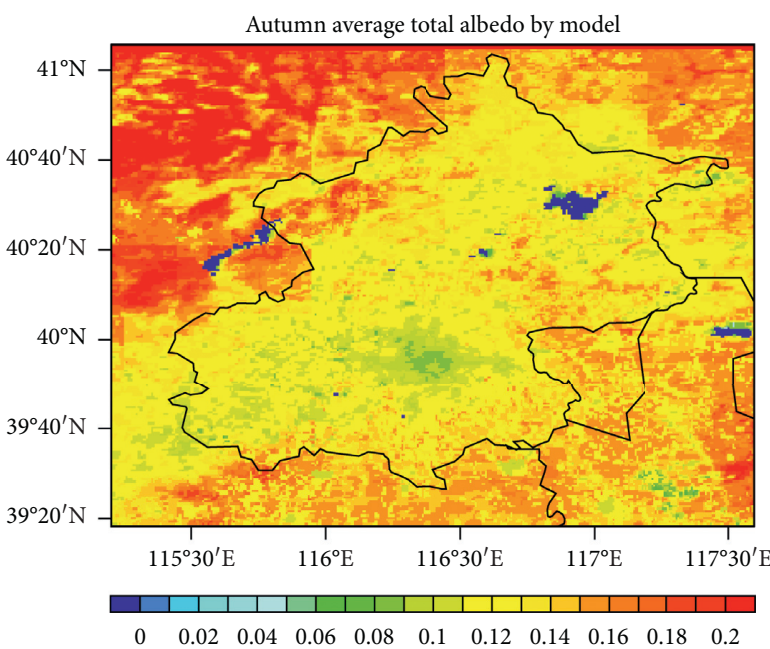

(d)

FIgURE 4: Continued. 


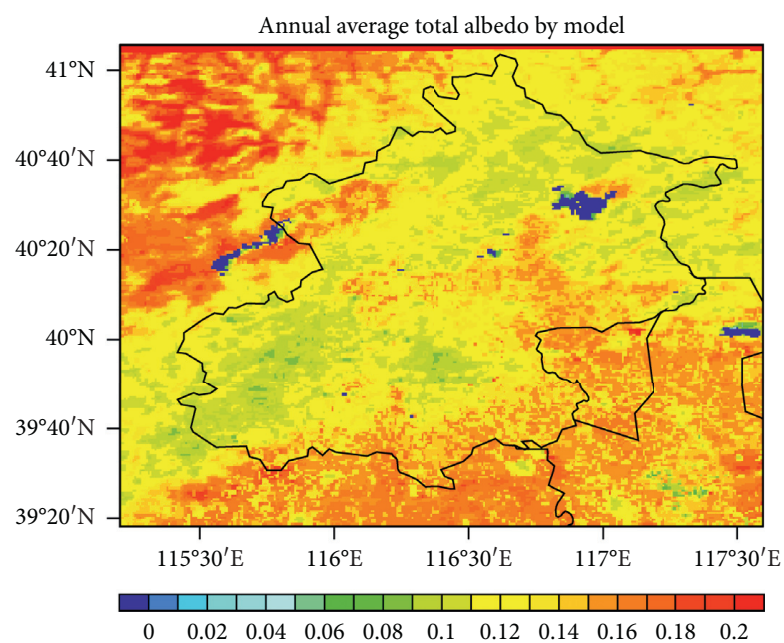

(e)

FIGURE 4: Spatial distribution of the annual (e) and seasonal (a-d) average surface albedo simulations after assimilation in the Beijing municipal area.

solar radiations, respectively; they are retrieved from MODIS. The surface albedo data set for the Beijing municipal area was generated based on the assimilation algorithm and MODIS data. The spatial and temporal resolution of the surface albedo data are $1 \mathrm{~km}$ and $1 \mathrm{~d}$, respectively.

\section{Results and Discussion}

First, in order to validate the accuracy of the surface albedo simulations before and after assimilation, we compared them with the observed surface albedos in the $325 \mathrm{~m}$ tower site. Figures 2(a) and 2(b) are the monthly and seasonal average surface albedo simulations before and after assimilation and the observations. The biases between the monthly average surface albedo simulations before and after assimilation and the observations are listed in Table 2. In the whole assimilation period, after assimilation, the albedo simulations are larger than those before assimilation. After assimilation, the biases are decreased apparently for all the months and seasons compared with those before assimilation.

Then, we compared the spatial distribution of the annual and seasonal average surface albedo simulations before (Figure 3) and after (Figure 4) assimilation in the Beijing municipal area. The differences (after assimilation minus before assimilation) between the simulation results before and after assimilation are plotted in Figure 5. For urban areas, the surface albedo simulations after assimilation are usually larger than those before assimilation. However, for other LUCs, the surface albedo simulations after assimilation are usually smaller than those before assimilation.

Then, we compared the annual and seasonal average surface albedo simulations before and after assimilation for different LUCs. Here, to simplify the comparison, we merged the LUCs of the research region into four main LUCs, that is, urban, cropland, forest, and grassland (Table 3). For most of the urban areas, the annual average surface albedo simulations after assimilation are larger than those before assimilation (Figure 6). However, for cropland, grassland, and forest areas, the annual average surface albedo simulations after assimilation are smaller than those before assimilation (Figure 6). Positive correlations exist for all the four LUCs, and the correlation coefficients between the simulations before and after assimilation for urban, cropland, grassland, and forest LUCs are $0.447,0.182,0.557$, and 0.570 , respectively.

We also compared the monthly average surface albedos for these four LUCs (Figure 7). For urban areas, the surface albedo simulations after assimilation are larger than those before assimilation for all the 12 months. However, for cropland, grassland, and forest areas, the surface albedo simulations after assimilation are smaller than those before assimilation for all the 12 months. For cropland, grassland, and forest areas, the surface albedo simulations before assimilation are relatively small in summer and large in winter; on the contrary, the surface albedo simulations after assimilation are relatively large in summer and small in winter. For cropland, grassland, and forest areas, the surface albedo simulations before and after assimilation are relatively large in November because of the snowfall and December because of the snow cover (Figure 8).

Surface albedo is associated with the upward solar radiation, so it is a crucial parameter in surface radiation budget. Figure 9 is the monthly average net radiation simulations before and after assimilation for the four main LUCs. Figure 10 is the scatter plot of the annual average albedo and net radiation simulation differences before and after assimilation for the four main LUCs (after 


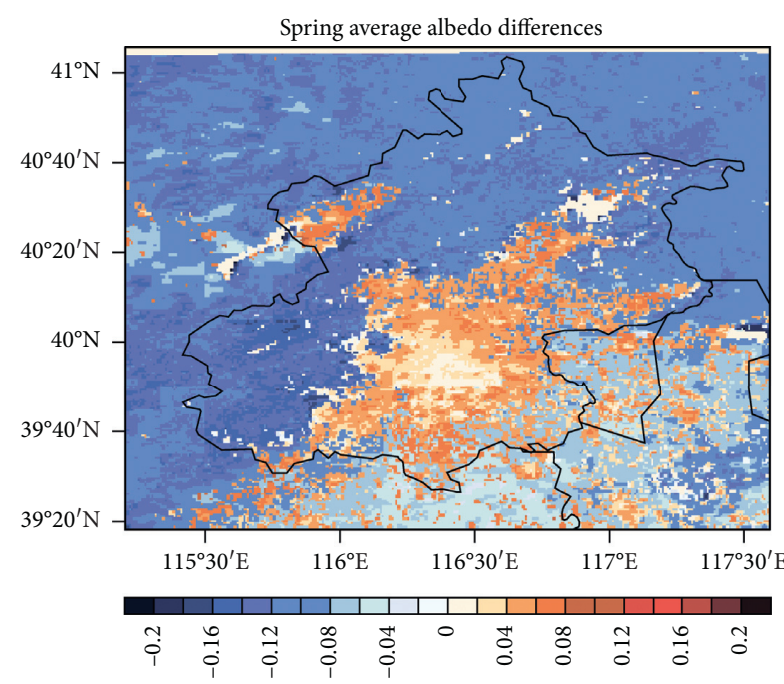

(a)

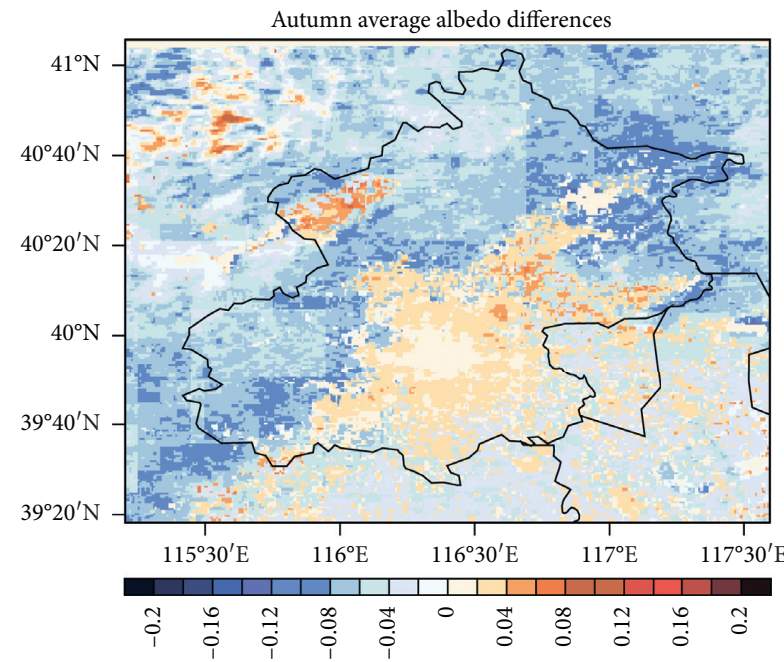

(c)

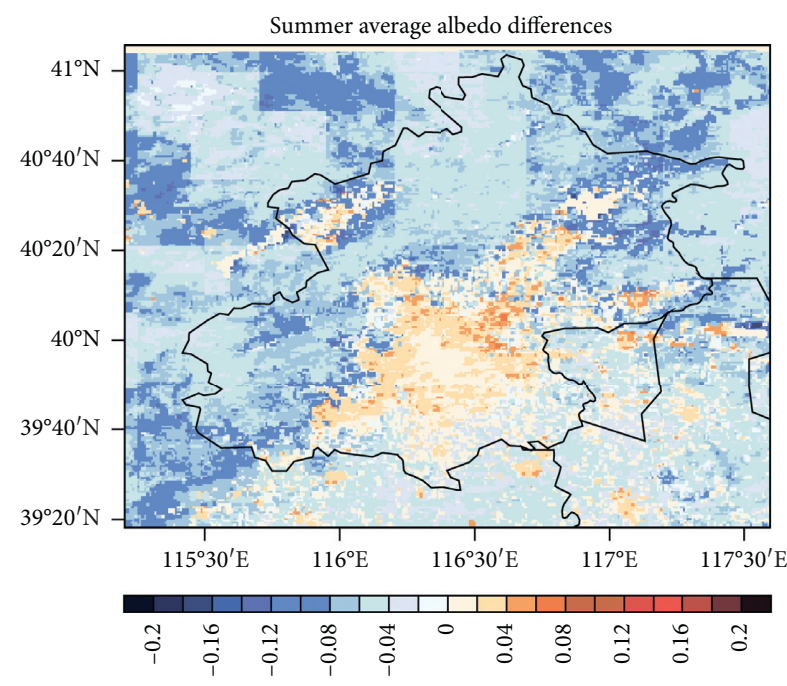

(b)

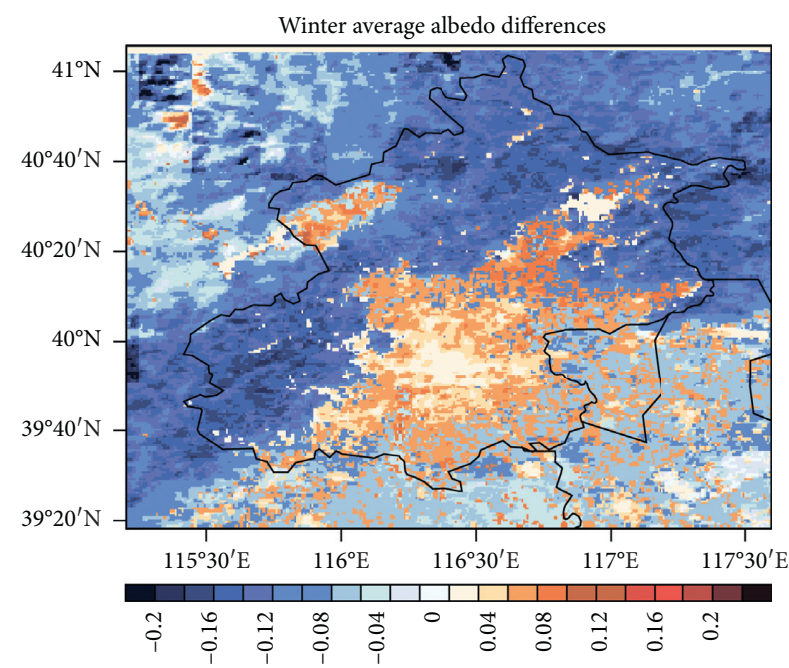

(d)

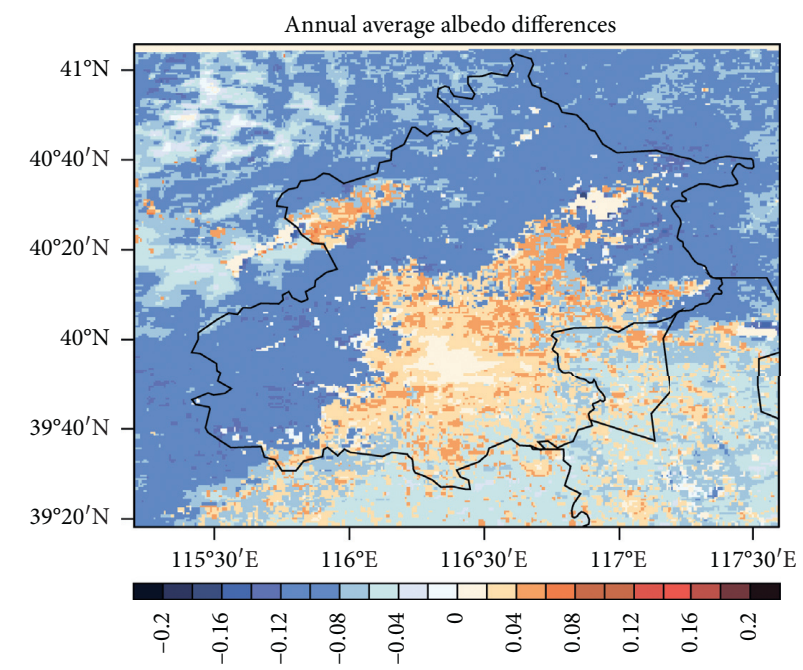

(e)

FigURE 5: Spatial distribution of the annual (e) and seasonal (a-d) average surface albedo simulation differences before and after assimilation in the Beijing municipal area (after assimilation minus before assimilation). 
TABle 3: Mapping for LUC merging.

LUC types LUC types after combination

Urban and built-up land

Dryland cropland and pasture

Urban

Cropland

Irrigated cropland and pasture

Mixed dryland/irrigated cropland and pasture

Cropland

Cropland/grassland mosaic

Cropland

Cropland/woodland mosaic

Cropland

Grassland

Cropland

Shrubland

Grassland

Mixed shrubland/grassland

Grassland

Savanna

Grassland

Deciduous broadleaf forest

Grassland

Deciduous needleleaf forest

Forest

Evergreen broadleaf forest

Forest

Evergreen needleleaf forest

Forest

Mixed forest.

Forest

Forest

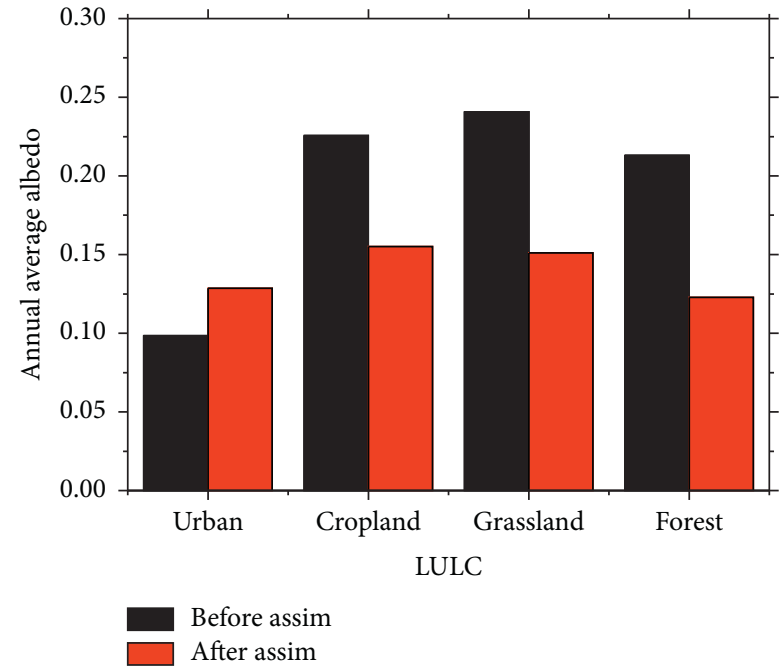

(a)

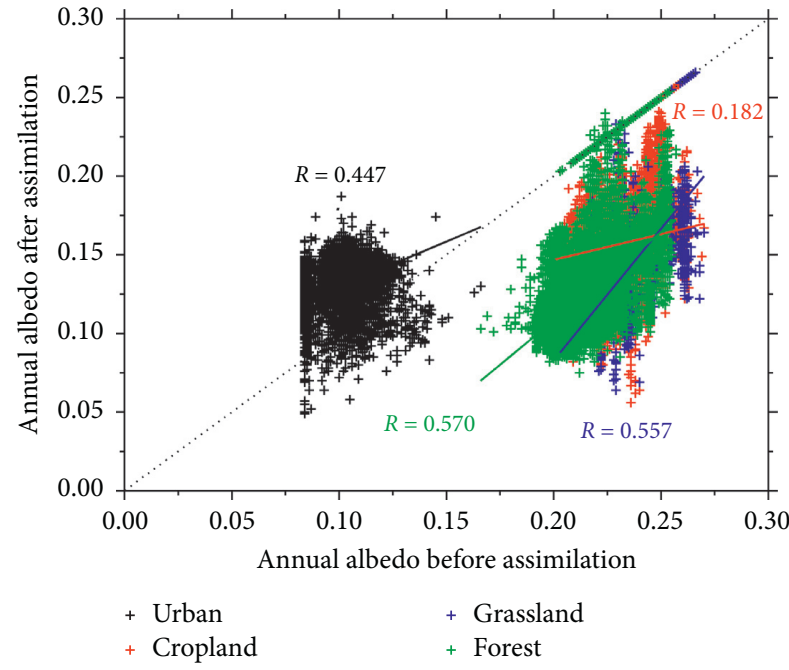

(b)

FIgURE 6: (a) Spatial average of the annual average albedo simulations before and after assimilation for the four main LUCs; (b) scatter plot of the annual average albedo simulations before and after assimilation for the four main LUCs.

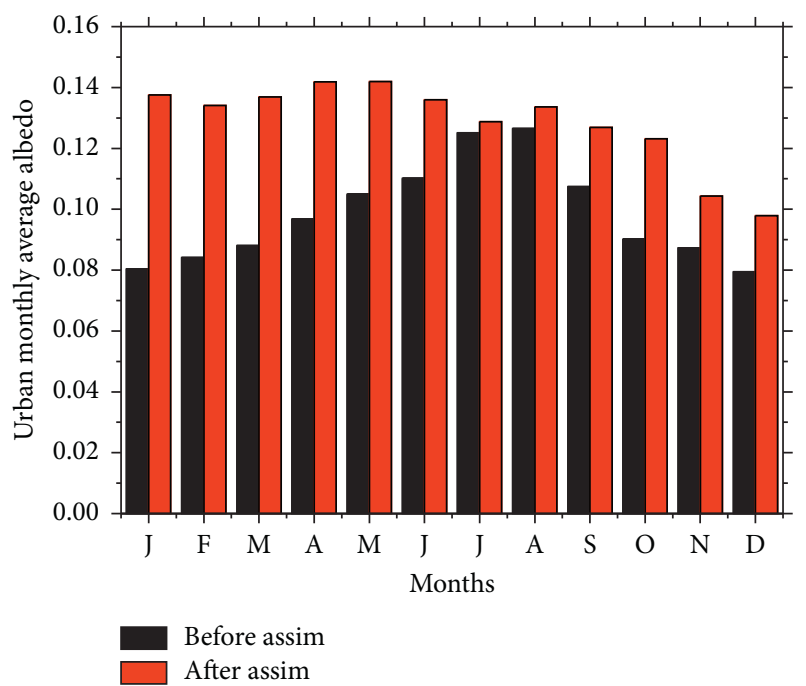

(a)

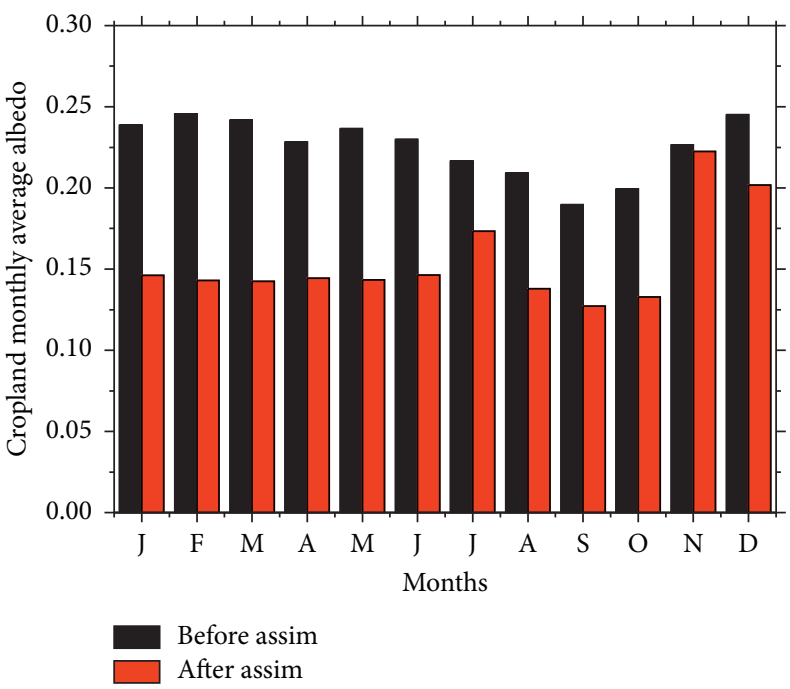

(b)

FIgURE 7: Continued. 


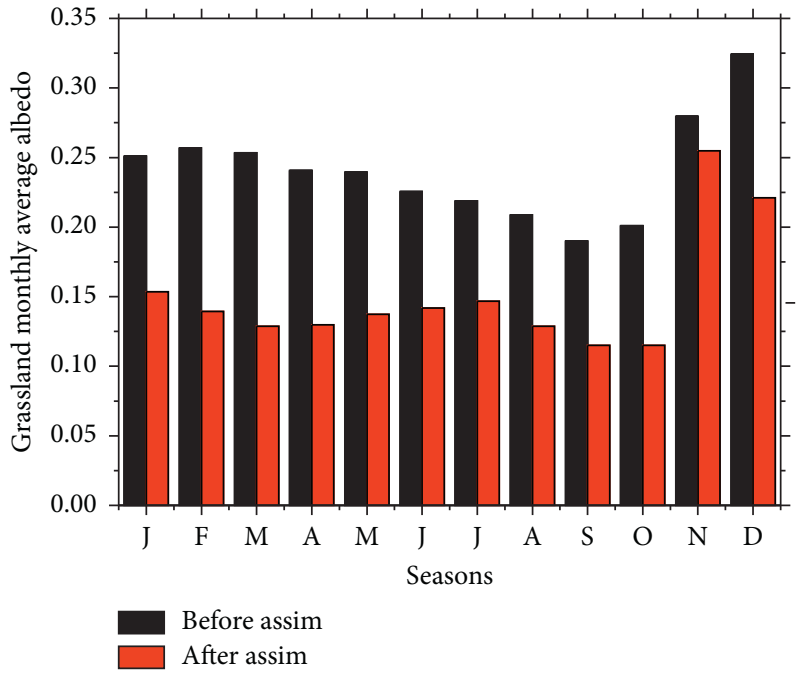

(c)

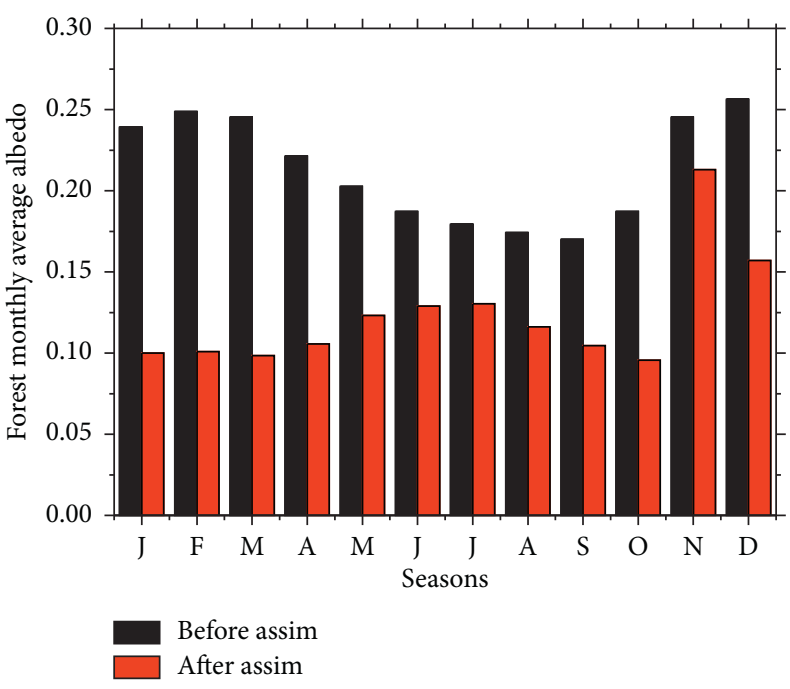

(d)

Figure 7: Spatial average of the monthly average albedo simulations before and after assimilation for the four main LUCs: (a) urban; (b) cropland; (c) grassland; (d) forest.

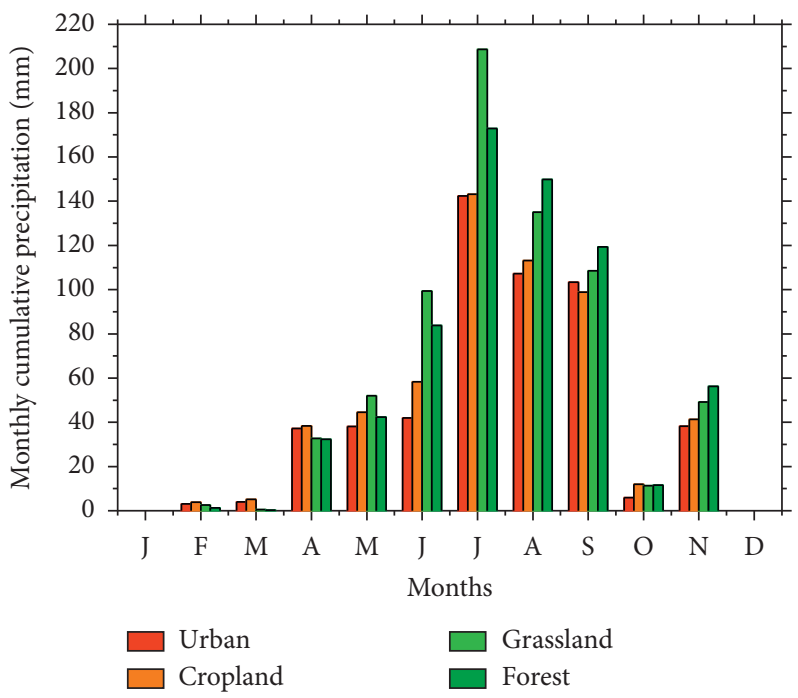

FIGURE 8: Spatial average of the monthly cumulative precipitation for the four main LUCs.

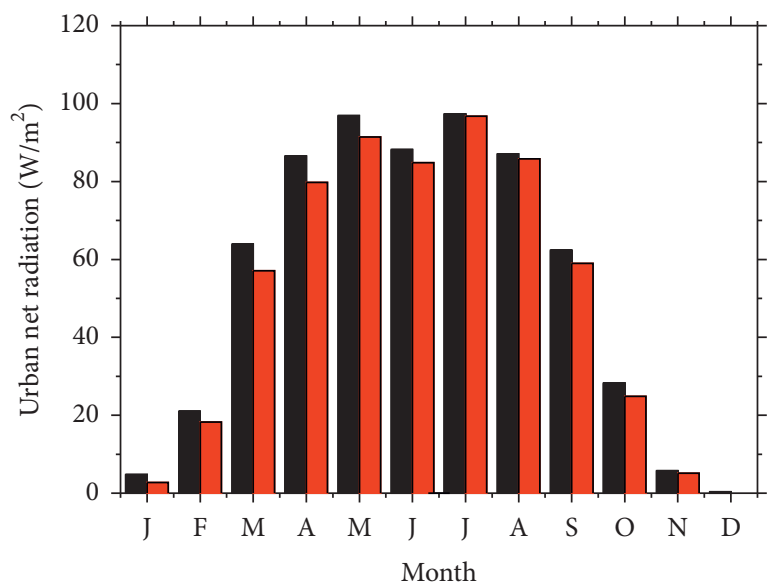

Before assim After assim

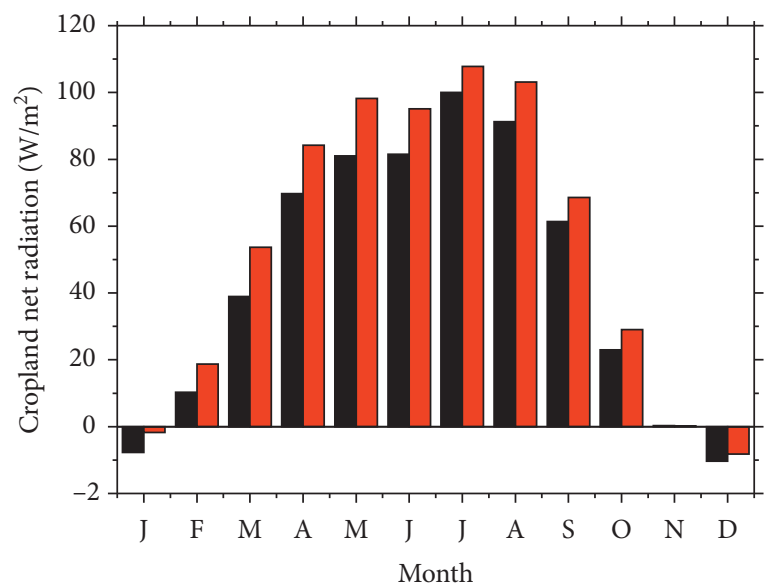

Before assim After assim

(a) 


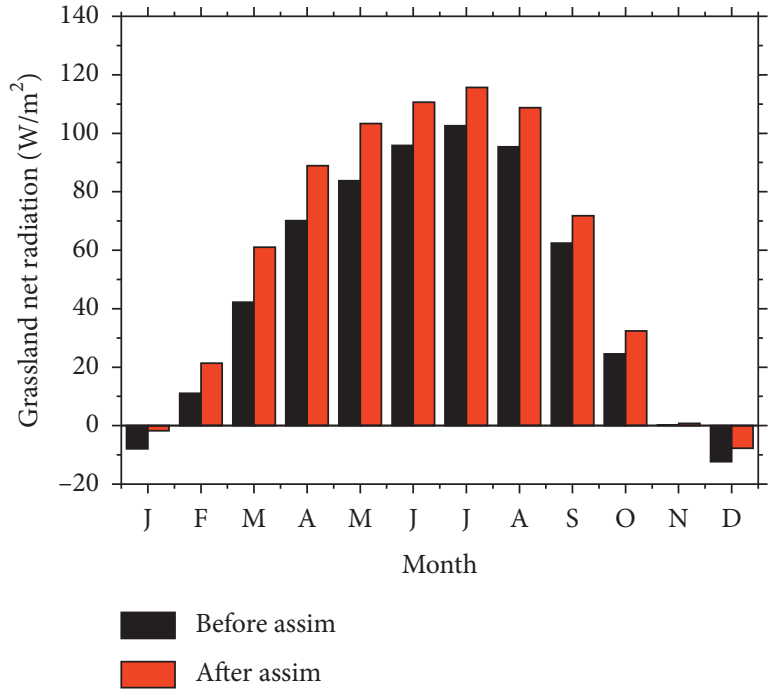

(c)

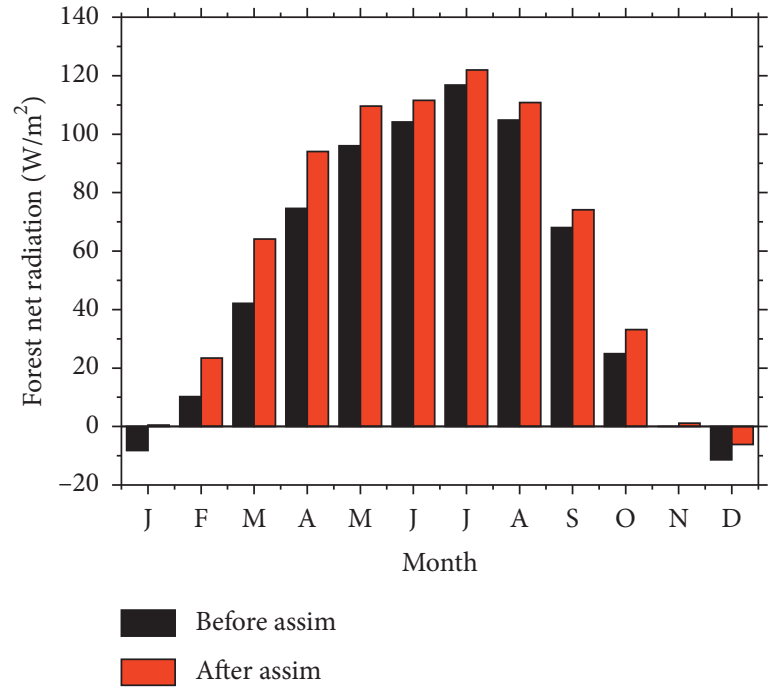

(d)

FIGURE 9: Spatial average of the monthly average net radiation simulations before and after assimilation for the four main LUCs: (a) urban; (b) cropland; (c) grassland; (d) forest.

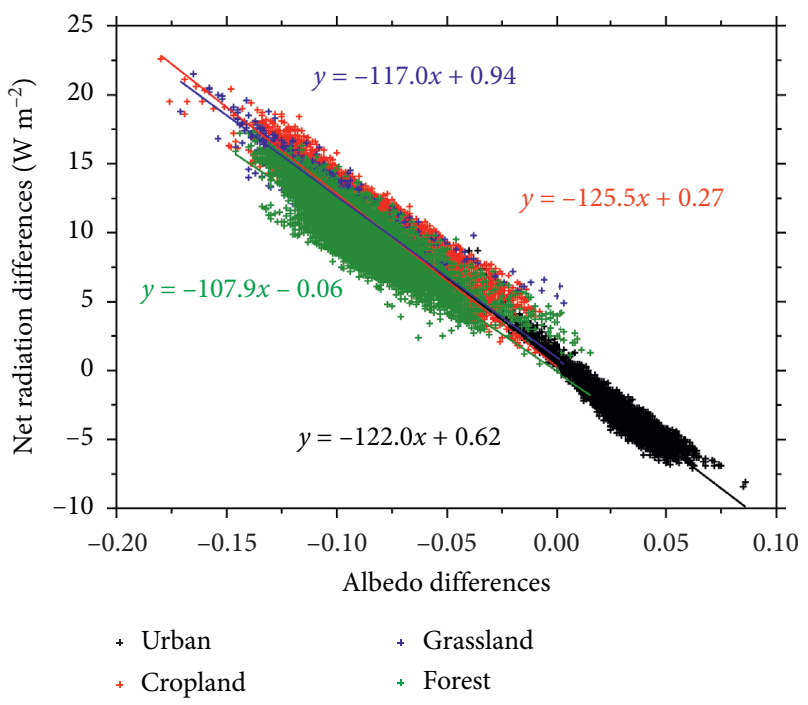

FIGURE 10: Scatter plot of the annual average albedo and net radiation simulation differences before and after assimilation for the four main LUCs (after assimilation minus before assimilation).

assimilation minus before assimilation). Albedo is inversely proportional to the net radiation. For urban areas, where the surface albedo simulations after assimilation are larger than those before assimilation, the net radiation simulations after assimilation are smaller than those before assimilation. However, for other LUCs, the net radiation simulations after assimilation are larger than those before assimilation.

Net radiation is not only associated with the upward solar radiation but also with the upward longwave radiation. As the upward longwave radiation is dependent on the surface radiative temperature, we compared the monthly average surface radiative temperature for these four LUCs (Figure 11). Figure 12 is the scatter plot of the annual average albedo and upward longwave radiation simulation differences before and after assimilation for the four main LUCs (after assimilation minus before assimilation). Albedo is inversely proportional to the upward longwave radiation. As the solar albedo increases, the solar radiation received by the land decreases; as a result, the surface radiative temperature and the upward longwave radiation decrease too.

The monthly average surface radiation budget simulations before and after assimilation for the four LUCs are shown in Figure 13. A quantitative analysis was performed for the impacts of the surface albedo on the surface radiation budget (Table 4). For urban areas, compared with that before assimilation, after assimilation, the annual average net radiation decreases about 5.6\%. For cropland, grassland, and forest areas, compared with those before assimilation, after 


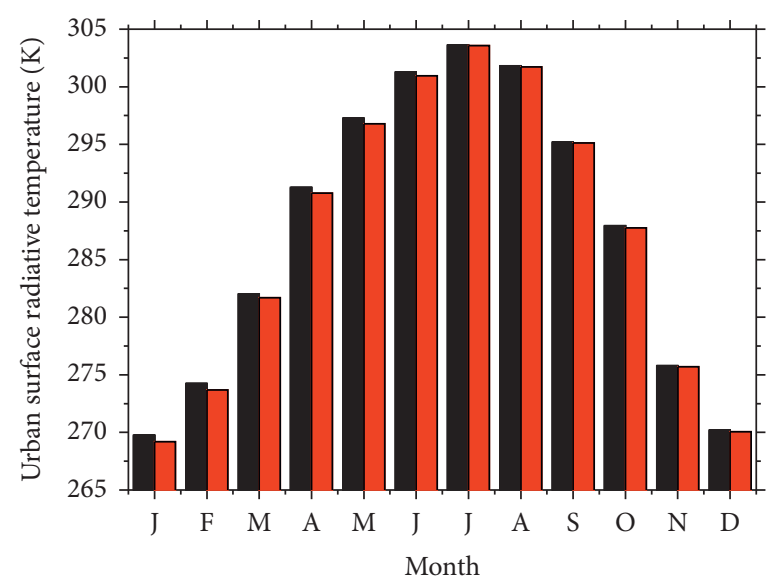

Before assim

After assim

(a)

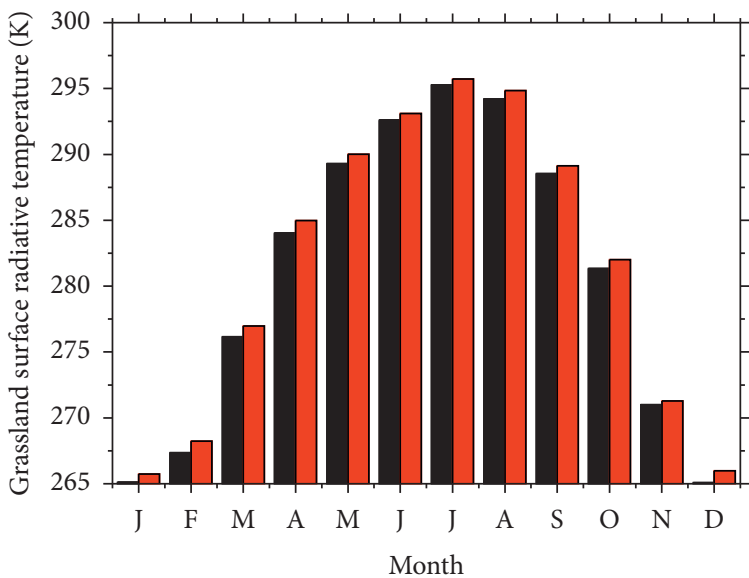

Before assim

After assim

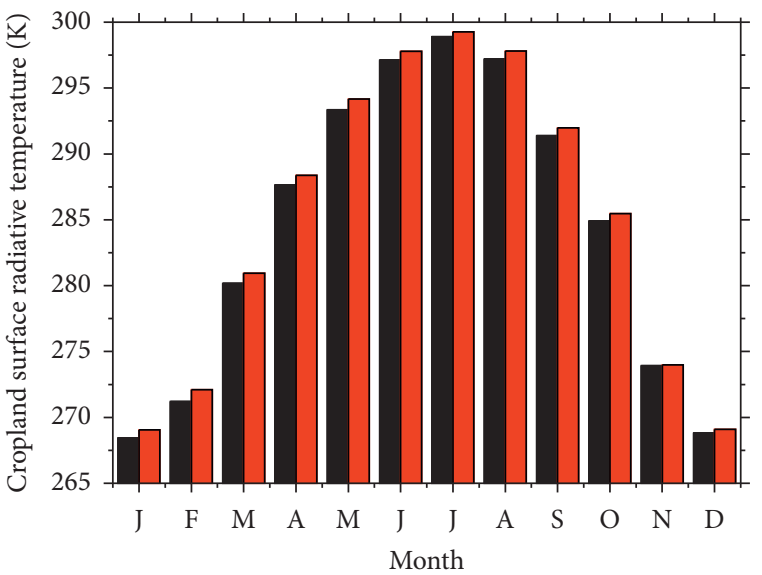

Before assim

After assim

(b)

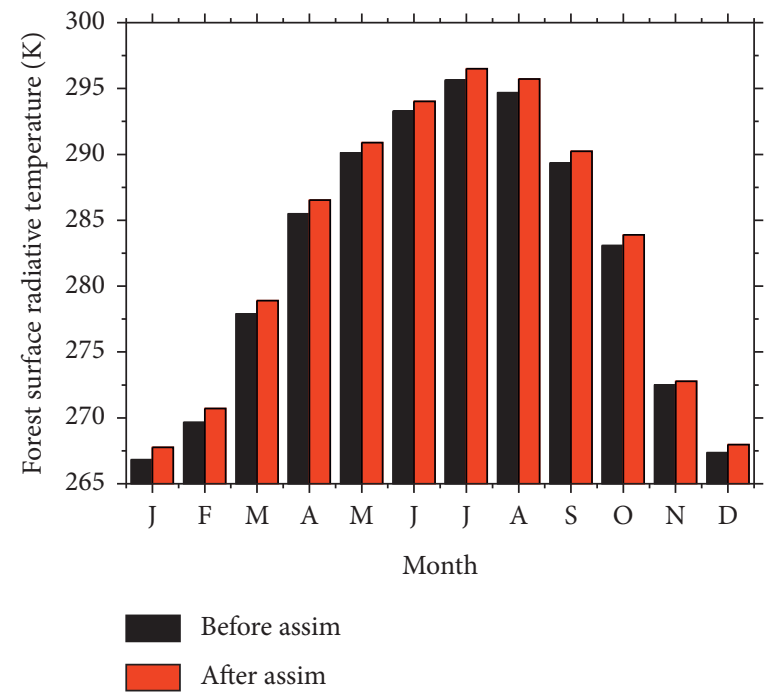

(d)

FIGURE 11: Spatial average of the monthly average surface radiative temperature simulations before and after assimilation for the four main LUCs: (a) urban; (b) cropland; (c) grassland; (d) forest.

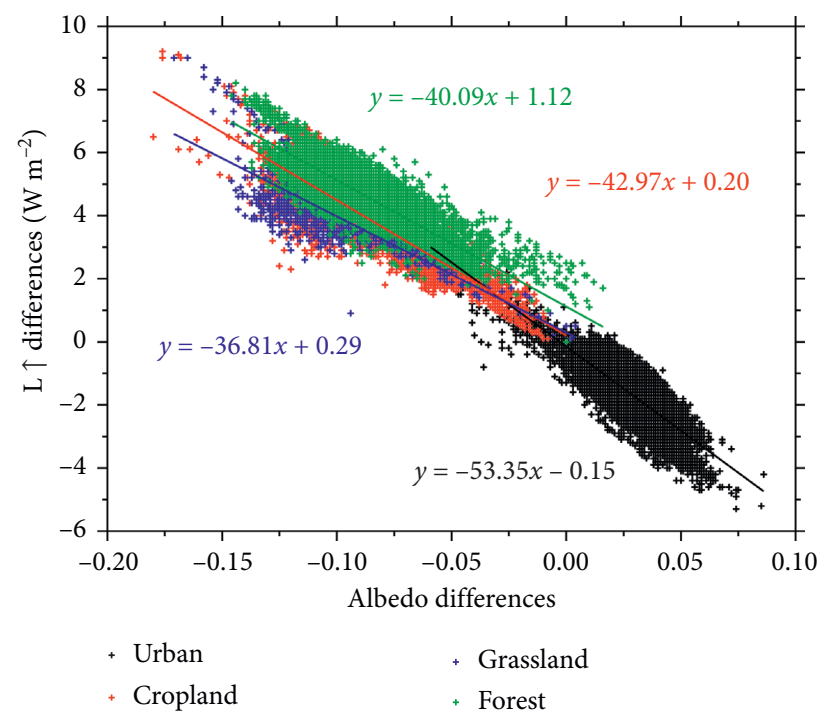

FIGURE 12: Scatter plot of the annual average albedo and upward longwave temperature simulation differences before and after assimilation for the four main LUCs (after assimilation minus before assimilation). 


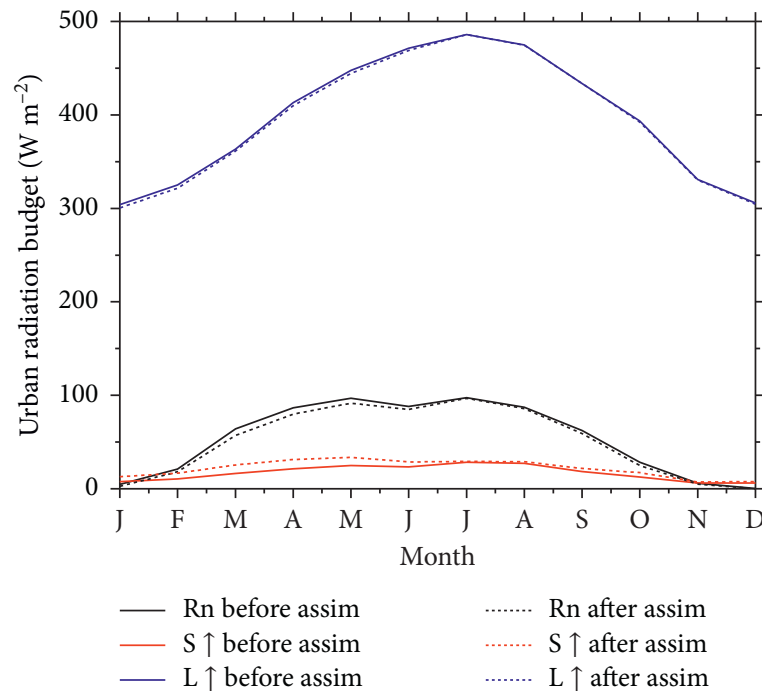

(a)

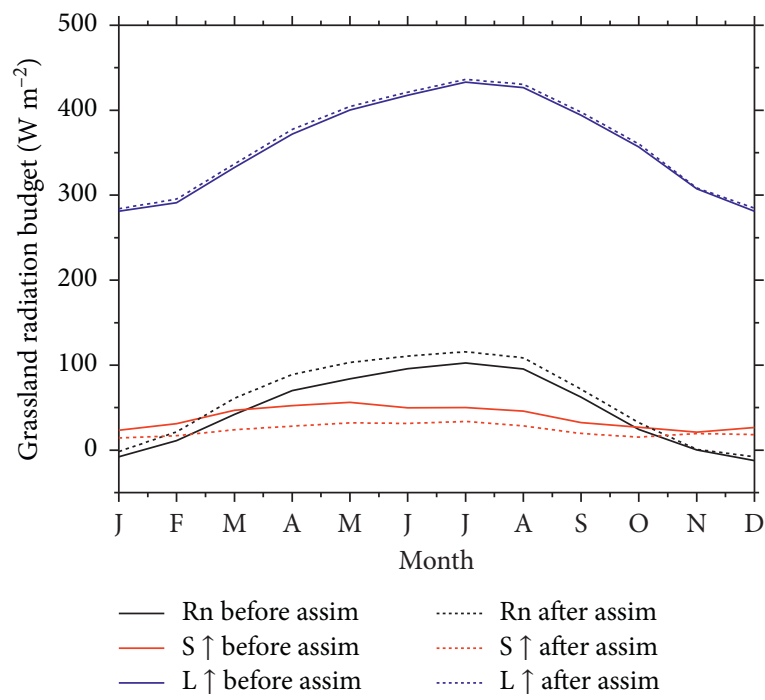

(c)

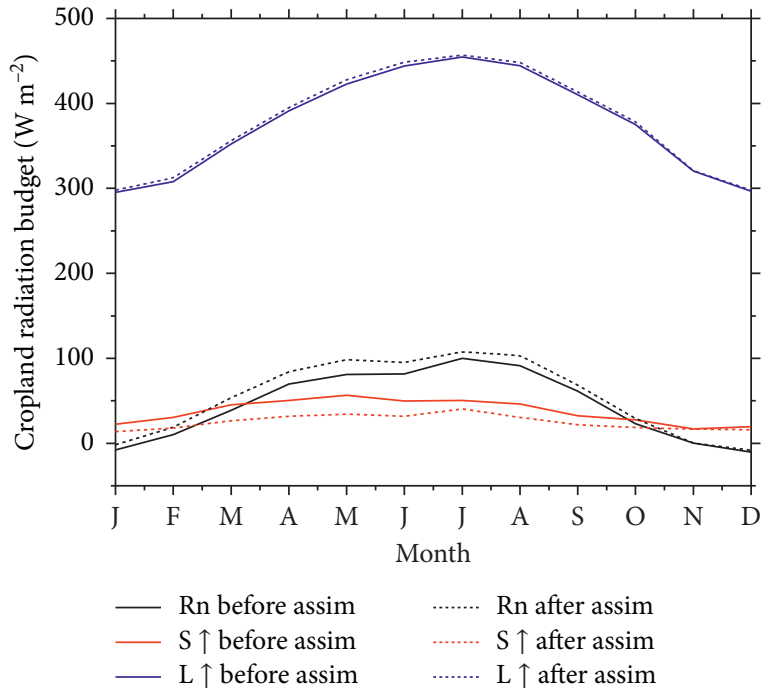

(b)

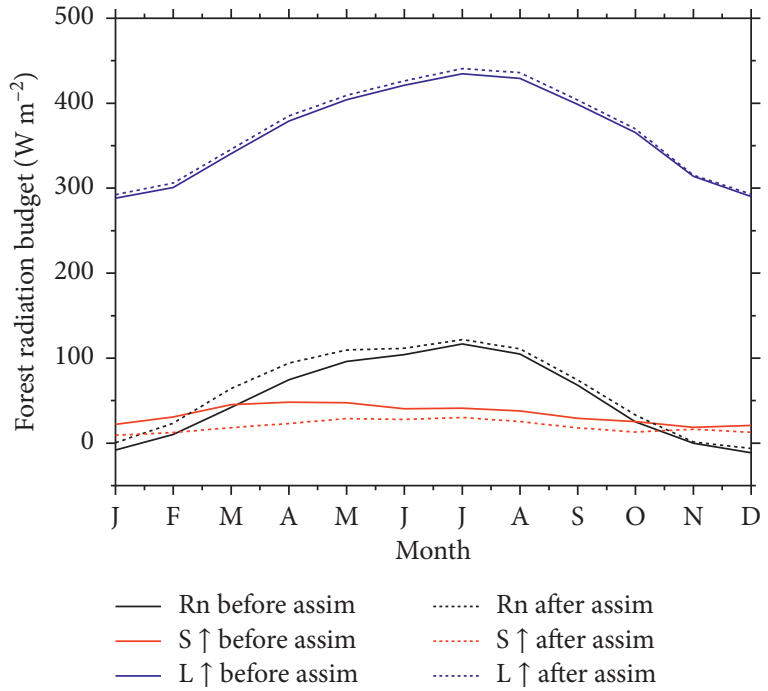

(d)

FIGURE 13: Spatial average of the monthly average radiation budget simulations before and after assimilation for the four main LUCs: (a) urban; (b) cropland; (c) grassland; (d) forest.

assimilation, the annual average net radiations increase about $20.2 \%, 24.3 \%$, and $18.7 \%$, respectively.

\section{Summary}

In this paper, the MODIS-retrieved direct visible, direct near-infrared, diffuse visible, and diffuse near-infrared surface albedos were assimilated into the IUM. The solar radiation partitioning method was introduced to parameterize the surface albedo. Based on the albedo data from MODIS and the solar radiation partitioning method, the surface albedo data set for the Beijing municipal area was generated. The surface albedo data were validated in the $325 \mathrm{~m}$ tower which was located in downtown Beijing. The result indicates that, after assimilation, the simulation results of the surface albedo are improved apparently.
Surface albedo is a crucial parameter in the surface radiation budget. The results indicate that the surface albedo is inversely proportional to the net radiation. For urban areas, compared with that before assimilation, after assimilation, the annual average net radiation decreases about $5.6 \%$. For cropland, grassland, and forest areas, compared with those before assimilation, after assimilation, the annual average net radiations increase about $20.2 \%, 24.3 \%$, and $18.7 \%$, respectively.

In the near future, the observed four components of the solar radiation should be used to validate the solar radiation partitioning methods. More observational sites should be used to validate the surface albedo data set. The generation algorithm of the surface albedo data set will be extended to a larger area such as the whole of China or the world. 
TABLE 4: Simulated annual average upward solar radiation, upward longwave radiation, and net radiation for urban, cropland, grassland, and forest LUCs before and after assimilation.

\begin{tabular}{cccc}
\hline \multicolumn{2}{c}{$\begin{array}{c}\text { Variables and } \\
\text { LUCs }\end{array}$} & Before assimilation & After assimilation \\
\hline \multirow{3}{*}{$\uparrow \quad$ Urban } & 16.9 & 21.7 \\
& Cropland & 37.3 & 25.0 \\
& Grassland & 38.6 & 23.5 \\
& Forest & 34.0 & 19.6 \\
\hline & Urban & 395.7 & 394.0 \\
$\mathrm{~L} \uparrow \quad$ Cropland & 376.2 & 379.5 \\
& Grassland & 357.8 & 361.4 \\
& Forest & 363.9 & 368.6 \\
\hline & Urban & 53.5 & 50.5 \\
$\mathrm{Rn} \quad$ Cropland & 45.0 & 54.1 \\
& Grassland & 47.3 & 58.8 \\
& Forest & 51.8 & 61.5 \\
\hline
\end{tabular}

\section{Data Availability}

The observational data from the $325 \mathrm{~m}$ tower station are from the Institute of Atmospheric Physics, Chinese Academy of Sciences, and are available in the supplementary materials.

\section{Conflicts of Interest}

The author declares that there are no conflicts of interest.

\section{Acknowledgments}

This work was supported by the National Natural Science Foundation of China under Grant nos. 41875125 and 41705086. The author thanks the Institute of Atmospheric Physics (IAP), Chinese Academy of Sciences (CAS), for $325 \mathrm{~m}$ Beijing meteorology tower observation data; MODIS for the LUC (http://glcf.umd.edu/data/lc/) and the surface albedo data (https://ladsweb.modaps.eosdis.nasa.gov/ search); and NASA for the GLDAS data (http://disc.sci. gsfc.nasa.gov/hydrology/data-holdings).

\section{Supplementary Materials}

The observational data from the Chinese Academy of Sciences $325 \mathrm{~m}$-high Meteorology and Environmental Observation Tower (325 $\mathrm{m}$ tower) are provided as the Supplementary Materials. (Supplementary Materials)

\section{References}

[1] J. Zhai, R. Liu, J. Liu, G. Zhao, and L. Huang, "Radiative forcing over China due to albedo change caused by land cover change during 1990-2010," Journal of Geographical Sciences, vol. 24, no. 5, pp. 789-801, 2014.

[2] A. Zhao, "The role of surface albedo feedback in climate," Journal of Climate, vol. 17, no. 7, pp. 1550-1568, 2004.

[3] M. Winton, "Surface albedo feedback estimates for the AR4 climate models," Journal of Climate, vol. 19, no. 3, pp. 359365, 2006.
[4] R. A. Colman, "Surface albedo feedbacks from climate variability and change," Journal of Geophysical Research: Atmospheres, vol. 118, no. 7, pp. 2827-2834, 2013.

[5] J. A. Crook and P. M. Forster, "Comparison of surface albedo feedback in climate models and observations," Geophysical Research Letters, vol. 41, no. 5, pp. 1717-1723, 2014.

[6] G. L. Stephens, D. O’Brien, P. J. Webster, P. Pilewski, S. Kato, and J.-l. Li, "The albedo of earth," Reviews of Geophysics, vol. 53, no. 1, pp. 141-163, 2015.

[7] Y. Pilewski, T. Wang, Z. Zeng, S. Peng, X. Lian, and S. Piao, "Evaluating biases in simulated land surface albedo from CMIP5 global climate models," Journal of Geophysical Research: Atmospheres, vol. 121, no. 11, pp. 6178-6190, 2016.

[8] A. Peng, M. Flanner, and J. Perket, "Multidecadal variability in surface albedo feedback across CMIP5 models," Geophysical Research Letters, vol. 45, no. 4, pp. 1972-1980, 2018.

[9] K. Wang, P. Wang, J. Liu, M. Sparrow, S. Haginoya, and $\mathrm{X}$. Zhou, "Variation of surface albedo and soil thermal parameters with soil moisture content at a semi-desert site on the western Tibetan Plateau," Boundary-Layer Meteorology, vol. 116, no. 1, pp. 117-129, 2005.

[10] Y. Sparrow, S. Lü, Y. Zhang, X. Meng, and S. Yang, "Improvement of surface albedo simulations over arid regions," Advances in Atmospheric Sciences, vol. 25, no. 3, pp. 481-488, 2008.

[11] H. Meng, B. Wang, and C. Fu, "Relationships between surface albedo, soil thermal parameters and soil moisture in the semiarid area of Tongyu, Northeastern China," Advances in Atmospheric Sciences, vol. 25, no. 5, pp. 757-764, 2008.

[12] F. Yang, K. Mitchell, Y.-T. Hou et al., "Dependence of land surface albedo on solar zenith angle: observations and model parameterization," Journal of Applied Meteorology and Climatology, vol. 47, no. 11, pp. 2963-2982, 2008.

[13] X. Dai, J. Huang, N. Guo, J. Bi, and G. Wang, "Variability of soil moisture and its relationship with surface albedo and soil thermal parameters over the Loess Plateau," Advances in Atmospheric Sciences, vol. 26, no. 4, pp. 692-700, 2009.

[14] S. Bi, Z. Wang, and S. Yang, "Parameterization of land surface albdeo," Chinese Optics Letters, vol. 12, no. 11, 2014.

[15] Z. Zheng, Z. Wei, Z. Wen et al., "Inclusion of solar elevation angle in land surface albedo parameterization over bare soil surface," Journal of Advances in Modeling Earth Systems, vol. 9, no. 8, pp. 3069-3081, 2017.

[16] Z. Dong, W. Dong, Z. Li et al., "Observational study of surface spectral radiation and corresponding albedo over Gobi, desert, and bare loess surfaces in northwestern China," Journal of Geophysical Research: Atmospheres, vol. 120, no. 3, pp. 883-896, 2015.

[17] C. Zhao and H. Li, "Solar radiation partitioning and surface albedo parameterization in the hinterland of Taklimakan desert," Advances in Meteorology, vol. 2019, Article ID 9098576, 8 pages, 2019.

[18] L. Zhou, R. E. Dickinson, Y. Tian et al., "Comparison of seasonal and spatial variations of albedos from moderateresolution imaging spectroradiometer (MODIS) and common land model," Journal of Geophysical Research, vol. 108, no. D15, p. 4488, 2003.

[19] B. Pinty, M. Taberner, V. R. Haemmerle et al., "Global-Scale comparison of MISR and MODIS land surface albedos," Journal of Climate, vol. 24, no. 3, pp. 732-749, 2011.

[20] T. Paradise, S. Liang, and D. Song, "Analysis of global land surface albedo climatology and spatial-temporal variation during 1981-2010 from multiple satellite products," Journal of Geophysical Research, vol. 119, no. 10, pp. 281-298, 2014. 
[21] S. Boussetta, G. Balsamo, E. Dutra, and C. Albergel, "Assimilation of surface albedo and vegetation states from satellite observations and their impact on numerical weather prediction," Remote Sensing of Environment, vol. 163, pp. 111-126, 2015.

[22] J. Beljaars, Q. Liu, J. Wen et al., "Multi-scale validation strategy for satellite albedo products and its uncertainty analysis," Science China Earth Sciences, vol. 58, no. 4, pp. 573-588, 2015.

[23] X. Liu, J. Wen, Q. Xiao et al., "Assessment of NPP VIIRS albedo over heterogenous crop land in Northern China," Journal of Geophysical Research, vol. 122, no. 13, pp. 138-154, 2017.

[24] S. Liang, M. Xu, W. Gao et al., "Mapping daily snow/ice shortwave broadband albedo from Moderate Resolution Imaging Spectroradiometer (MODIS): the improved direct retrieval algorithm and validation with Greenland in situ measurement," Journal of Geophysical Research, vol. 110, no. D10, p. D11107, 2005.

[25] M. J. Malik, R. van der Velde, and Z. Vekerdy, "Assimilation of satellite-observed snow albedo in a land surface model," Journal of Hydrometeorology, vol. 13, no. 3, pp. 1119-1130, 2012.

[26] J. Su and H. Shu, "Assimilating MODIS-based albedo and snow cover fraction into the Common Land Model to improve snow depth simulation with direct insertion and deterministic ensemble Kalman filter methods," Journal of Geophysical Research: Atmospheres, vol. 119, no. 18, pp. 684-710, 2014.

[27] P. Vahmani and G. A. Ban-Weiss, "Impact of remotely sensed albedo and vegetation fraction on simulation of urban climate in WRF-urban canopy model: a case study of the urban heat island in Los Angeles," Journal of Geophysical Research: Atmospheres, vol. 121, no. 4, pp. 1511-1531, 2016.

[28] H. Fang, S. Liang, H.-Y. Kim et al., "Developing a spatially continuous $1 \mathrm{~km}$ surface albedo data set over North America from Terra MODIS products," Journal of Geophysical Research, vol. 112, no. D20, p. D20206, 2007.

[29] E. G. Townshend, M. D. King, and C. B. Schaaf, "MODISderived spatially complete surface albedo products: spatial and temporal pixel distribution and zonal averages," Journal of Applied Meteorology and Climatology, vol. 47, no. 11, pp. 2879-2894, 2008.

[30] A. Platnick, B. Marcolla, S. K. Santhana Vannan et al., "Intercomparison of MODIS albedo retrievals and in situ measurements across the global FLUXNET network," Remote Sensing of Environment, vol. 121, pp. 323-334, 2012.

[31] D. Pan, C. Meurey, X. Ceamanos, J.-L. Roujean, J.-C. Calvet, and S. Liu, "Dynamic mapping of snow-free vegetation and bare soil albedos at global $1 \mathrm{~km}$ scale from 10 -year analysis of MODIS satellite products," Remote Sensing of Environment, vol. 140, pp. 420-432, 2014.

[32] D. Roujean, S. Liang, T. He, Y. Yu, C. Schaaf, and Z. Wang, "Estimating daily mean land surface albedo from MODIS data," Journal of Geophysical Research: Atmospheres, vol. 120, no. 10, pp. 4825-4841, 2015.

[33] J. Yu, C. A. Barnes, M. S. Nash, and T. G. Wade, "Combining NLCD and MODIS to create a land cover-albedo database for the continental United States," Remote Sensing of Environment, vol. 170, pp. 143-152, 2015.

[34] Q. Wade, Z. Wang, Z. Li, and C. B. Schaaf, "Evaluation of the global MODIS 30 arc-second spatially and temporally complete snow-free land surface albedo and reflectance anisotropy dataset," International Journal of Applied Earth Observation and Geoinformation, vol. 58, pp. 36-49, 2017.

[35] A. Erb and J. M. Norman, "Partitioning solar radiation into direct and diffuse, visible and near-infrared components," Agricultural and Forest Meteorology, vol. 34, no. 2-3, pp. 205-213, 1985.

[36] M. Rodell, P. R. Houser, U. Jambor et al., "The global land data assimilation system," Bulletin of the American Meteorological Society, vol. 85, no. 3, pp. 381-394, 2004.

[37] C. Gottschalck, "The integrated urban land model," Journal of Advances in Modeling Earth Systems, vol. 7, no. 2, pp. 759773, 2015.

[38] Y. Dai, X. Zeng, R. E. Dickinson et al., "The common land model," Bulletin of the American Meteorological Society, vol. 84, no. 8, pp. 1013-102410, 2003. 